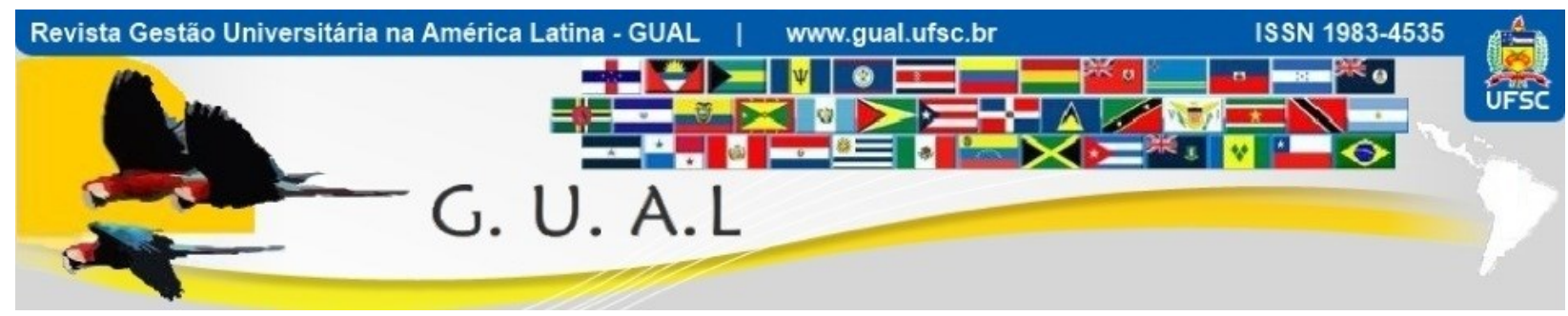

DOI: http://dx.doi.org/10.5007/1983-4535.2016v9n2p282

\title{
OS DESAFIOS DA MOBILIDADE ACADÊMICA PARA A GESTÃO UNIVERSITÁRIA: UM SURVEY COM GRADUANDOS DA UDESC
}

\author{
THE ACADEMIC MOBILITY CHALLENGES FOR THE UNIVERSITY \\ MANAGEMENT: A SURVEY WITH UDESC'S UNDERGRADUATE STUDENTS
}

Monique Raupp, Mestranda Universidade Federal do Rio Grande do Sul - UFRGS mony_raupp@hotmail.com

Marco Antônio Seifriz, Doutor Universidade do Estado de Santa Catarina - UDESC marco.seifriz@gmail.com

Recebido em 24/julho/2014

Aprovado em 18/novembro/2015

Sistema de Avaliação: Double Blind Review

Esta obra está sob uma Licença Creative Commons Atribuição-Uso. 


\title{
RESUMO
}

A internacionalização do ensino superior brasileiro vem chamando a atenção da produção acadêmica, investigando-se tendências como o incremento da mobilidade acadêmica em diferentes países, a adoção de matrizes curriculares transnacionais e a formação de redes internacionais de pesquisa científica. Na Universidade do Estado de Santa Catarina (UDESC), mais particularmente, este processo encontra-se em seus estágios iniciais, criando a necessidade de entender-se melhor o impacto do fenômeno da internacionalização no que tange a gestão universitária. Este estudo tem como objetivo identificar os principais desafios e dificuldades encontrados pelos estudantes de graduação da Escola Superior de Administração e Gerência (ESAG) da UDESC ao participarem de um programa de mobilidade acadêmica em universidades estrangeiras. Foi realizado um survey junto a 208 graduandos entre os anos de 2009 e 2013, utilizando-se entrevistas semiestruturadas por meio digital. Os resultados obtidos indicam que a experiência da mobilidade é vista pelos estudantes, predominantemente, como uma oportunidade de desenvolvimento pessoal, e que os obstáculos enfrentados são principalmente de ordem de registro acadêmico. No tocante a gestão universitária, discute-se a criação de um instrumento de apoio virtual com vistas a dinamizar o atendimento aos alunos em mobilidade.

Palavras-chave: Internacionalização. Instituições de ensino superior. Mobilidade acadêmica.

\begin{abstract}
The internationalization of Brazilian higher education has attracted the attention of academic production, by investigating trends as increasing academic mobility in different countries, the adoption of transnational curriculum matrices and the consolidation of international networks of scientific research. At the University of the State of Santa Catarina (UDESC) this process is in its early stages, creating the need to understand the impact of internationalization phenomenon in relation to university management. This study aims to identify the main challenges and difficulties encountered by undergraduate students of the School of Business and Management (ESAG), department of UDESC, to participate in an academic mobility program in foreign universities. A survey was conducted with 208 undergraduates between the years 2009 and 2013, using semi-structured interviews by digital means. The results indicate that the mobility experience is seen by the students, predominantly, as an opportunity for personal development, and the obstacles faced by the students are mostly bureaucratic, such as validating courses taken abroad and knowing the foreign documents necessary for the local registry. Regarding the university management, it is discussed the creation of a virtual instrument support with the objective of streamlining the service to students in mobility.
\end{abstract}

Keywords: Internationalization. Higher education institutions. Academic mobility. 


\section{INTRODUÇÃO}

No ambiente da economia global há um fenômeno em crescente expansão denominado internacionalização de Instituições de Ensino Superior (IES). Este processo está cada vez mais presente no cenário acadêmico brasileiro, seja por meio da mobilidade acadêmica de estudantes e professores, seja pelo oferecimento de programas de pós-graduação certificados ou credenciados em nível internacional ou pela consolidação de redes de projetos de pesquisa conjuntos entre países.

De acordo com Knight (2004), a internacionalização do ensino superior é um processo de integração em escala internacional e intercultural nas funções de ensino, pesquisa e extensão de uma instituição. Busca-se uma mudança organizacional nas universidades capaz de formar uma cultura de valorização dos enfoques internacionais, interculturais e interdisciplinares, permitindo assim a promoção e o apoio de iniciativas para a interação, a cooperação e o intercâmbio com instituições de outros países.

Diante deste contexto, a produção científica na área da mobilidade acadêmica é crescente, atestando a importância do tema na medida em que o processo de internacionalização das IES acaba gerando impactos sobre a sua estrutura organizacional e, por consequência, revelando novos desafios para o campo da gestão universitária.

A recente literatura mundial no campo da internacionalização do ensino superior oferece um bom número de indicadores para avaliar-se o grau de internacionalização de uma determinada instituição, embora ainda esteja longe de consolidar um framework teórico capaz de oferecer um modelo capaz de explicar cientificamente este fenômeno.

Sebastian (2004) fez um levantamento destes indicadores, revelando que a mobilidade acadêmica é um dos componentes mais importantes para medir-se o grau de internacionalização de uma IES, devendo receber especial atenção dos esforços de gestão universitária. Bett (2012) constatou que "no momento anterior à viagem, os estudantes não têm clareza em relação ao que buscam com o intercâmbio". É comum terem medo do desconhecido e, em virtude disto, procuram conhecer um pouco mais sobre a cultura escolhida antes da chegada ao novo país.

Este estudo tem como objetivo levantar as principais dificuldades enfrentadas no exterior pelos graduandos da Escola Superior de Administração e Gerência (ESAG) ao participarem dos programas de mobilidade acadêmica da UDESC, no intuito de oferecer 
novos subsídios para as atividades de suporte aos programas de articulação internacional no âmbito das IES.

Neste particular, a autora desta pesquisa teve esta experiência ao cursar a quarta fase do curso de Graduação em Administração da ESAG em uma universidade na França, levando-nos a crer que seria propositado uma investigação científica sobre estas dificuldades, bem como sugestões para as atividades locais de suporte acadêmico à luz da bibliografia especializada.

$\mathrm{Na}$ perspectiva de se tentar consolidar as indagações levantadas pela revisão bibliográfica e de se buscar uma relação entre mobilidade acadêmica e gestão universitária, formulou-se então o seguinte problema de pesquisa: quais são os principais desafios e dificuldades encontrados pelos estudantes de graduação da ESAG que aderiram ao programa de mobilidade acadêmica internacional da UDESC durante o período compreendido entre 2009 e $2013 ?$

\section{REVISÃO BIBLIOGRÁFICA}

O ensino superior vem assistindo à consolidação de tendências como o incremento da mobilidade acadêmica de estudantes e professores em diferentes países, a adoção de matrizes curriculares transnacionais, a oferta de cursos de graduação e pós-graduação credenciados em diversos países e a formação de redes internacionais de pesquisa científica. De fato, com a globalização dos mercados e com os novos modos de comunicação não verbais, o conhecimento e a informação passaram a ser desterritorializados. O restrito espaço do pesquisador acabou ampliando-se para um espaço virtual, havendo, portanto, que se debater se tais mudanças tratam da negação da ideia de universidade ou de novas possibilidades de realidade com as quais teremos que viver.

Laus (2012) argumenta que, ao contrário do que muitos pensam, o processo de internacionalização de IES não é um fenômeno da contemporaneidade. As IES foram criadas no século XI e sua estrutura têm incentivado a mobilidade de seus estudantes e professores desde a Idade Média, época em que o latim era o idioma utilizado para a comunicação entre a elite e parte da nobreza.

No Brasil, essa realidade demorou um pouco mais para ser consolidada. O fenômeno deu-se em decorrência de forças externas internacionais e forças internas como a necessidade de um desenvolvimento científico e tecnológico e da disseminação do conhecimento 
acadêmico. Foi apenas no final dos anos 1990 que a Coordenação de Aperfeiçoamento de Pessoal de Nível Superior (CAPES) manifestou a necessidade do estabelecimento de padrões internacionais para a avaliação das atividades de pós-graduação e das pesquisas dela decorrentes desenvolvidas pelas IES públicas brasileiras. Foi a partir deste momento que se expandiu o fenômeno da internacionalização de IES brasileiras.

Não obstante as críticas, as universidades brasileiras vêm melhorando suas posições nos rankings internacionais. Esses rankings são instrumentos que conferem visibilidade internacional às instituições e vêm encorajando a competição no nível nacional e internacional na busca de um padrão identificado com o que se convencionou chamar de "universidades padrão mundial”.

No contexto internacional, destacamos o ranking feito pela Folha de São Paulo, o Ranking Universitário Folha (RUF). Trata-se de uma pesquisa realizada utilizando indicadores como número de trabalhos publicados e citações baseados em diferentes aspectos da presença das instituições na web, tais como visibilidade, tamanho, produtividade e impacto. Entre seus critérios, estão incluídos indicadores de pesquisa e de qualidade de estudantes e docentes, além da visibilidade e o desempenho global da instituição medido pelos acessos via internet aos artigos por elas produzidos. A Universidade Federal do Estado de Santa Catarina (UFSC) é a universidade catarinense mais internacionalizada e ocupa a $12^{\mathrm{a}}$ posição nacional. A UDESC ocupa o segundo lugar no Estado, mas apenas a $128^{\mathrm{a}}$ posição nacional (RUF, 2014).

\subsection{MOBILIDADE ACADÊMICA}

A mobilidade acadêmica tradicionalmente pode ser classificada, segundo Kiley \& Austin (2008), em quatro tipos: a mudança para outro lugar após o término do ensino médio para realizar algum curso de graduação; mudança para outro lugar para realizar parte da graduação; mobilidade virtual (mobilidade realizada pelo uso da internet); e mudança para outro lugar para realizar a pós-graduação. Para Mccarthy et al. (2012), a globalização e as crescentes oportunidades empregatícias em corporações multinacionais e em outros países ajudaram a impulsionar o crescimento da educação transfronteiriça, quebrando as barreiras internacionais por meio das facilidades de acesso a novas culturas, o que levou ao despertar do interesse por conhecimentos e experiências diferentes dos que adquirimos em nosso país. Os autores também constatam que os governos perceberam o potencial econômico dos 
estudantes internacionais e alocaram mais recursos para melhorar a educação superior em seus países e para aumentar o número de estudantes internacionais. Esses talentosos estudantes também fornecem uma força de trabalho local que pode contribuir para pesquisas e inovações.

Vaicekauskas et al. (2013) argumentam que a experiência internacional e o aperfeiçoamento de competências pessoais auxiliam o estudante a se destacar em meio a um grupo de pessoas que não realizaram algum tipo de intercâmbio cultural e profissional, tratando-se da inserção de ambos no mercado de trabalho.

Segundo Gribble (2008), há várias razões para o crescimento dos programas de mobilidade acadêmica no mundo, como a facilidade de acesso a eles com a diminuição dos custos dos programas e avanços nas tecnologias de comunicação e a crença de que o programa desenvolverá habilidades e conhecimentos profissionais do estudante.

De acordo com o Ministério do Turismo (2010), dos 100 milhões de estudantes de nível superior no mundo no ano de 2010, três milhões estavam em mobilidade no exterior, e a previsão é a de que, até 2020, esse número alcance os 10 milhões. Na Europa, por exemplo, o programa de mobilidade acadêmica mais popular entre os estudantes universitários é o European Region Action Scheme for the Mobility of University Students (ERASMUS), um programa de intercâmbio estudantil criado em 1987 que oferece aos estudantes universitários a possibilidade de estudar e trabalhar em um país europeu. Diversos programas mundiais são oferecidos com este fim, sendo o Ciência Sem Fronteiras ${ }^{1}$ um forte atuante nacional. "Embora os EUA continuem a ser o maior país receptor, seguido do Reino Unido, França, Austrália e Alemanha, novos receptores como Japão, África do Sul, Rússia e Itália despontam também neste ranking" (UNESCO, 2009). Segundo Salles (2008), o país que mais internacionaliza seus estudantes é a China, sendo responsável por aproximadamente $15 \%$ dos intercambistas no mundo. Mccarthy et al. (2012) constatam que mais de $90 \%$ dos estudantes internacionais escolhem países membros da Organização para a Cooperação e Desenvolvimento Econômico (OCDE) como os Estados Unidos, a Grã Bretanha e a Austrália, que são responsáveis pelo acolhimento de aproximadamente $45 \%$ dos intercambistas do mundo.

\footnotetext{
1 Segundo o site Ciências sem Fronteiras, o programa "busca promover a consolidação, expansão e internacionalização da ciência e tecnologia, da inovação e da competitividade brasileira por meio do intercâmbio e da mobilidade internacional. A iniciativa é fruto de esforço conjunto dos Ministérios da Ciência, Tecnologia e Inovação (MCTI) e do Ministério da Educação (MEC), por meio de suas respectivas instituiçães de fomento CNPq e Capes -, e Secretarias de Ensino Superior e de Ensino Tecnológico do MEC".
} 
Para Mccarthy et al. (2012), um dos motivos que estudantes internacionais são atraídos para universidades estadunidenses é devido à reputação do país como possuidor de um dos melhores e mais prestigiados sistemas acadêmicos. De acordo com o Institute of International Education (IIE, 2014), no período compreendido entre 2011 e 2012, cerca de 1 a cada 2 estudantes de mobilidade acadêmica nos EUA era da área de negócios, sendo $30 \%$ da graduação e $17 \%$ do mestrado. No país, aproximadamente $28 \%$ destes estudantes são intercambistas.

Lee (2013) fala que, tanto para os estudantes estadunidenses quanto para os estrangeiros se beneficiarem desta experiência da melhor forma, as universidades devem oferecer um bom suporte para a aculturação dos intercambistas durante o período inicial de suas mobilidades, ajudando-os nos problemas relacionados à interação com os estudantes nativos, ao convívio com estes na sala de aula e em atividades extracurriculares. $\mathrm{O}$ autor também constata que "barreiras linguísticas e importantes diferenças culturais foram se tornando crescentemente aparentes na segregação dos estudantes estadunidenses e dos intercambistas" (LEE, 2013). O caso mais frequente, no entanto, e talvez o mais desafiador, é do grande distanciamento cultural, caso da China e de alguns países da América Latina, causado pela educação dada por estes países de uma maneira mais individualista. Isto pode ser observado não apenas no caso dos Estados Unidos, mas, para muitos países, estes são problemas recorrentes.

Para Vaicekauskas et al. (2013), o convívio com professores estrangeiros, estudantes e funcionários de diferentes culturas enfatiza naturalmente a atmosfera internacional de institutos de educação superior e oferece aos estudantes possibilidades de aprender a agir em um ambiente multicultural.

No caso do Brasil, argumenta Salles (2008), acordos para intercâmbio de conhecimentos técnico-científicos e culturais, em especial voltados às IES, vêm sendo firmados há mais de trinta anos. Atitudes como estas têm o forte potencial de disseminar conhecimento que poderão ser transmitidos às gerações futuras.

Não existem dados institucionais acerca da mobilidade total de estudantes, professores e pesquisadores das IES brasileiras. Desta forma, utilizamos dados do CNPq e da CAPES analisados por Laus (2012), para apresentar um pouco da realidade do Brasil neste contexto. No período compreendido entre 2001 e 2008, a concessão de bolsas pela Capes para graduação e doutorado sanduíche aumentou a cada ano, como também é o caso das bolsas 
para pós-doutorado. Para estas situações em que o período de estudos no exterior é pequeno e há uma intenção de retorno ao Brasil, estes estudantes poderão fortalecer as instituições brasileiras com os conhecimentos adquiridos nas instituições do exterior, geralmente altamente desenvolvidas e, assim, há uma "retenção de cérebros", ou seja, esses estudiosos permanecerão no Brasil contribuindo, desta forma, com o desenvolvimento do país. O mestrado e mestrado sanduíche foram as modalidades com os menores números entre as citadas, sendo que, no ano de 2008, não foi cedida nenhuma bolsa para o último. Esta situação pode ser explicada pelos altos investimentos feitos desde a década de 1960 na qualificação e fortalecimento dos programas de pós-graduação brasileiros, que hoje são considerados, ao menos os mestrados, com qualidade suficiente para atender à demanda dos brasileiros.

Para Gribble (2008), a educação superior de alta qualidade e o ambiente que suporta e encoraja pesquisas e inovações tornaram o Brasil um polo regional na referida área, atraindo um grande número de estudantes e de pesquisadores estrangeiros.

\subsubsection{Motivações da mobilidade acadêmica}

Para Llewellyn-Smith e Mccabe (2008), os estudantes que realizam mobilidade acadêmica podem ser chamados de "turistas educacionais", expressão que nomeia as pessoas que viajam a algum lugar e participam, tanto formal como informalmente, de algum tipo de experiência educativa disponível no local. As autoras dividem este grupo em dois segmentos: “educação primeiro" e "turismo primeiro". No primeiro caso, o aprendizado e a educação são as principais motivações dos estudantes para a realização da mobilidade acadêmica. Já o segundo segmento abrange estudantes que têm o desejo de viajar e se divertir como motivações mais importantes do que estudar. Em sua pesquisa, realizada com estudantes universitários estrangeiros de uma universidade australiana, constataram que o desejo dos estudantes de viajar e a oportunidade de ter uma experiência divertida e empolgante são as principais motivações para que participem de programas de mobilidade acadêmica, junto à importância do clima do país escolhido, suas atrações turísticas e o ambiente natural deste. As autoras constataram que seria interessante para o departamento de marketing das universidades enfatizarem mais as possibilidades de realizar turismo e de se divertir em seus materiais educacionais sobre mobilidade acadêmica.

De acordo com Kiley e Austin (2008), a realização da mobilidade acadêmica é influenciada pelo nível de acesso às instituições. Quanto mais alto, menos provável será que 
os estudantes a escolherão. Os autores realizaram uma pesquisa com estudantes de pósgraduação australianos e constataram que havia duas principais razões que estes deram para ir à outra universidade. Viram este processo como uma maneira de expandir suas experiências universitárias e acreditavam que haveria melhores oportunidades em outras universidades em comparação às suas.

Mccarthy et al. (2012) argumentam que estudantes, principalmente de países em desenvolvimento, pensam que, em algumas situações, seus países deixam a desejar quando se trata do fornecimento de oportunidades de qualidade que eles precisam nas IES, assim buscando o preenchimento desta lacuna por meio de uma viagem a nações desenvolvidas. Os autores também concluem que os estudantes optam por sair de seus países devido à dificuldade em conseguir estudar em universidades locais porque a competição para fazer parte delas é muito elevada, pela existência de uma área especializada em seus estudos em algum outro país ou porque estes estudos desenvolvidos são reconhecidos em seus países natais.

Para Bett (2012), as motivações que levam os estudantes universitários a realizarem um programa de mobilidade acadêmica podem ser divididas em 3 grupos: motivações acadêmicas (aprimoramento de conhecimentos específicos e idiomas, realizar contatos acadêmicos, obtenção de certificado, entre outros); motivações relacionadas ao crescimento pessoal (ampliação da visão de mundo, conhecimento de novas culturas, fazer amigos de outras nacionalidades, entre outros); e motivações relacionadas ao lazer (viajar e conhecer lugares novos, divertir-se). Ressalta que o grupo com uma maior variedade de respostas foi o de crescimento pessoal, sendo que, dos 18 tipos de motivações citados na pesquisa da mencionada autora, 12 pertencem a esta categoria. No entanto, constata que o grupo com a maior quantidade de respostas foi o de motivações acadêmicas. Identifica que as motivações que mais se destacaram em sua pesquisa foram as buscas pela ampliação da visão do mundo e do desenvolvimento de conhecimentos específicos. Algumas dificuldades e desafios comuns que os estudantes universitários encontram ao realizar mobilidade acadêmica, segundo a autora, são a adaptação à nova cultura, o idioma local, a adaptação ao ensino e a saudade dos que ficaram no país de origem. Considera que para enfrentar tais questões, são necessárias, de uma maneira geral, habilidades como estar aberto às novas experiências, ter tolerância, respeito e uma boa interação com os habitantes locais e empenhar-se nos estudos. Sugere que, para que esses problemas sejam minimizados, seria interessante uma preparação para a 
mobilidade acadêmica antes desta ser realizada, trazendo benefícios tanto para os estudantes como também para as instituições que os receberão e aquelas de origem.

\subsubsection{A Gestão da mobilidade acadêmica}

Apesar do processo de mobilidade acadêmica ter melhorado muito com o passar dos anos, pesquisas mostram que ainda há lacunas a serem preenchidas e oportunidades a serem exploradas. É o que explicam Beeck et al. (2007), que estudaram um projeto chamado Virtual Mobility Before and After Student Exchanges (VM-BASE), desenvolvido para auxiliar virtualmente os estudantes tanto antes como depois de realizarem o programa de mobilidade acadêmica. Consideram que a mobilidade virtual tem dois principais propósitos: tornar a mobilidade física uma experiência mais enriquecedora, complementando-a virtualmente; e ser uma alternativa à mobilidade física sem as implicações financeiras desta, possibilitando aos estudantes a participação em aulas em outras universidades sem a necessidade de sair da sua. Os autores chamaram a primeira situação de blended mobility, expressão que, traduzida, significa mobilidade mista, "misturada". Esta situação foi o enfoque do trabalho deles que, com o intuito de sugerir maneiras das IES auxiliarem seus estudantes que realizarão um programa de mobilidade acadêmica, dividiram este tipo de mobilidade em duas etapas: a etapa realizada antes da mobilidade física e a etapa realizada depois da mobilidade física dos estudantes.

\begin{tabular}{|c|c|}
\hline Suporte virtual antes da mobilidade física & Suporte virtual depois da mobilidade física \\
\hline Guias de orientação & Avaliação virtual a distância \\
\hline Informações sobre os cursos & Alunos virtuais \\
\hline Ferramentas de pré-seleção e seleção estudantil & \\
\hline Cursos preparatórios & \\
\hline
\end{tabular}

Quadro 1 Possíveis atividades de suporte virtual para a mobilidade acadêmica.

Fonte: Beeck et al. (2007)

Para os mencionados autores, o suporte virtual antes da realização da mobilidade física permite ao estudante se preparar previamente para o programa de mobilidade de seu próprio país, auxílio este que é raro de ser encontrado atualmente. Os guias de orientação devem ser elaborados com informações fornecidas por todos os parceiros dos programas de mobilidade (ex-estudantes internacionais, funcionários da universidade hospedeira) para auxiliar os futuros intercambistas, como qual universidade escolher e como fazê-lo, como se ambientar à nova cultura e universidade antes de ir, entre outros. As informações corretas e claras sobre os 
cursos são essenciais para o bom andamento da mobilidade, tendo em vista que muitas vezes os estudantes estrangeiros não possuem prévio acesso a todas as informações necessárias na hora da seleção das disciplinas da nova universidade, ou até mesmo estas estão desatualizadas. É importante que todas essas informações sejam sempre atualizadas, disponibilizadas de forma clara e em ao menos dois idiomas (o local e, caso este não seja o Inglês, possuir neste idioma também). Há casos em que estudantes estrangeiros não possuem muito conhecimento tecnológico, por exemplo, e as atividades da disciplina são realizadas em determinados programas, ou o estudante escolheu uma disciplina no idioma local mas, ao iniciar as aulas, percebeu que não conseguirá acompanhar, pois não possui conhecimento o suficiente do idioma. As ferramentas de pré-seleção seriam uma maneira do professor e da própria instituição saber se os estudantes que desejam fazer a disciplina têm as características necessárias para se inscrever nela, selecionando assim apenas os que forem considerados aptos. Apesar de que a maioria das universidades hospedeiras possui cursos preparatórios para seus estudantes internacionais como cursos do idioma local, a grande parte deles não é oferecida virtualmente. A sugestão do projeto VM-BASE é a de serem oferecidos três tipos de cursos preparatórios virtuais aos estudantes de mobilidade acadêmica: cursos de linguagem (do idioma local da instituição hospedeira), cursos culturais (sobre a história e cultura do país hospedeiro, da estrutura, organização e tradições acadêmicas da instituição hospedeira) e cursos de alfabetização digital (por exemplo um ambiente de aprendizado digital que é utilizado pela instituição hospedeira e que requer treinamento prévio). Ressalta-se também a possibilidade da utilização de um buddy system, em que estudantes locais guiam os futuros intercambistas pela rotina da instituição local e de seu país.

Beeck et al. (2007) também consideram sobre a importância do suporte virtual depois da realização da mobilidade física, tendo em vista que poderá ser avaliada a experiência que o estudante teve durante o seu programa de mobilidade acadêmica e também para reforçar as redes de contato conquistadas por ele no outro país. A avaliação virtual a distância servirá como uma ferramenta de apoio aos professores tanto da instituição hospedeira quanto da instituição local do estudante que realizou a mobilidade acadêmica. Eles não apenas poderão avaliar a totalidade do programa em relação ao desempenho do estudante, como também poderão aplicar provas ou atividades quando este reprovou em alguma matéria ou ainda falta terminar algum trabalho na instituição do outro país, se ele já retornou ao seu país de origem. Por último, foi constatado que os ex-estudantes estrangeiros são a melhor maneira de 
despertar o interesse de possíveis futuros intercambistas e podem ser um fator valioso para o crescimento do programa de mobilidade acadêmica. Por esta razão, haveria a necessidade da busca das informações dos mencionados estudantes nos arquivos das instituições hospedeiras, para que seja formado um banco de dados que poderia servir para encorajar atuais intercambistas a manterem contato com a instituição hospedeira, seus colegas e professores; quem sabe, inclusive, para retornar e realizar novos cursos. Para que todas estas implementações sejam feitas adequadamente, os autores destacam que o projeto VM-BASE prestará muita atenção no e-coaching dos professores e estudantes participantes deste programa, ou seja, os ensinará e auxiliará a utilizar todas as atividades da mobilidade virtual.

No caso estudado por Madlena et al. (2008), estudantes romenos de administração que já realizaram um programa de mobilidade acadêmica escrevem um relatório descrevendo a experiência que tiveram no outro país. As informações obtidas por meio desses feedbacks são repassadas pelo Departamento de Programas Comunitários da universidade aos estudantes que pretendem participar de um programa de mobilidade acadêmica. Questões como custo de vida diários e maneiras de utilizar o tempo livre são exemplos de algumas destas informações.

\section{METODOLOGIA}

Esta pesquisa é predominantemente descritiva e quantitativa, pois procura relatar a realidade dos alunos de graduação da ESAG/UDESC que participaram de programas de mobilidade acadêmica com base em dados obtidos por meio de um questionário semi estruturado disponibilizado em ambiente on line.

A população de referência consiste nos graduandos da ESAG que realizaram programas de mobilidade acadêmica internacional oferecidos pela UDESC no período compreendido entre 2009 e 2013. Para obter esta relação, buscamos auxílio na Secretaria de Cooperação Interinstitucional e Internacional (SCII) da UDESC que, por meio do seu sistema acadêmico, ofereceu uma lista de e-mails de 208 estudantes que compõem a população escolhida.

O procedimento utilizado para o estudo foi um survey, uma técnica considerada adequada pelo estudo para obter-se rápidas respostas a partir da amostra, para que, consequentemente, descubra-se a incidência relativa das variáveis a serem estudadas (HAIR Jr. et al., 2005). 
A partir da revisão bibliográfica, foi elaborado um questionário semiestruturado abrangendo questões para o desenvolvimento deste trabalho. O questionário foi apresentado em versão eletrônica utilizando-se o Google Docs, software gratuito muito comum para a condução de pesquisas acadêmicas on-line. O link de acesso à webpage do questionário foi oferecido por meio de mensagem eletrônica à população escolhida.

A estrutura geral do questionário incluiu 14 questões objetivas e 2 questões abertas. As questões objetivas tinham o propósito de conhecer melhor o perfil dos estudantes e suas experiências durante o intercâmbio, enquanto as questões abertas buscavam compreender como eles lidaram com os problemas que surgiram durante o período em questão.

O acesso ao questionário foi disponibilizado entre os dias 03/09 e 21/09 de 2014. Após o tratamento dos dados, obtivemos uma amostra de 63 respostas válidas sobre uma população de 192 estudantes em mobilidade.

Os dados obtidos foram analisados na ordem em que as perguntas foram feitas, individualmente. Para questões mais objetivas, como gênero e idade dos estudantes, por exemplo, a análise foi feita de uma forma literal, sem a utilização de tabelas ou gráficos. Nas questões mais qualitativas, consideramos importante ilustrarmos os resultados obtidos para a sua posterior análise. Em um destes casos, utilizamos o método de categorização das questões, dividindo-as em grupos conforme o nível de complementariedade entre elas. Desta forma, as alternativas de características similares foram agrupadas, o que facilitaria também a sua posterior análise. Este método foi baseado no trabalho de Bett (2012), no qual a autora criou este tipo de categorização com o intuito de melhor esclarecer os resultados encontrados e de facilitar a sua interpretação.

\section{DESCRIÇÃO E ANÁLISE DOS DADOS COLETADOS}

Os dados coletados revelam que, nas 63 respostas válidas que compõem a amostra, a divisão de gênero está equilibrada, sendo que 33 eram homens e 30 mulheres. Em relação à faixa etária quando realizaram o programa de mobilidade acadêmica, 67\% dos estudantes possuíam entre 19 e 22 anos e 30\% possuíam idade compreendida entre 23 e 26 anos.

O curso que mais enviou estudantes ao exterior foi o de Administração Empresarial, representando $78 \%$ deste total, enquanto os cursos de Economia e Administração pública tiveram participações consideravelmente menores, com apenas 14\% e $8 \%$ dos estudantes enviados, respectivamente. 
Como motivos mais relevantes para a escolha do país, há a facilidade com o idioma oficial e identificação tanto com a imagem como com a cultura do país. $\mathrm{O}$ fácil acesso a outros países para turismo chama a atenção de $61 \%$ dos estudantes. A importância atribuída ao prestígio da instituição como fator de escolha não obteve uma resposta predominante.

O Gráfico 1 apresenta os principais países de destino da mobilidade, percebendo-se uma clara predominância da França e da Alemanha. Importante salientar que esses países possuem o maior número de convênios de mobilidade acadêmica celebrados com a UDESC.

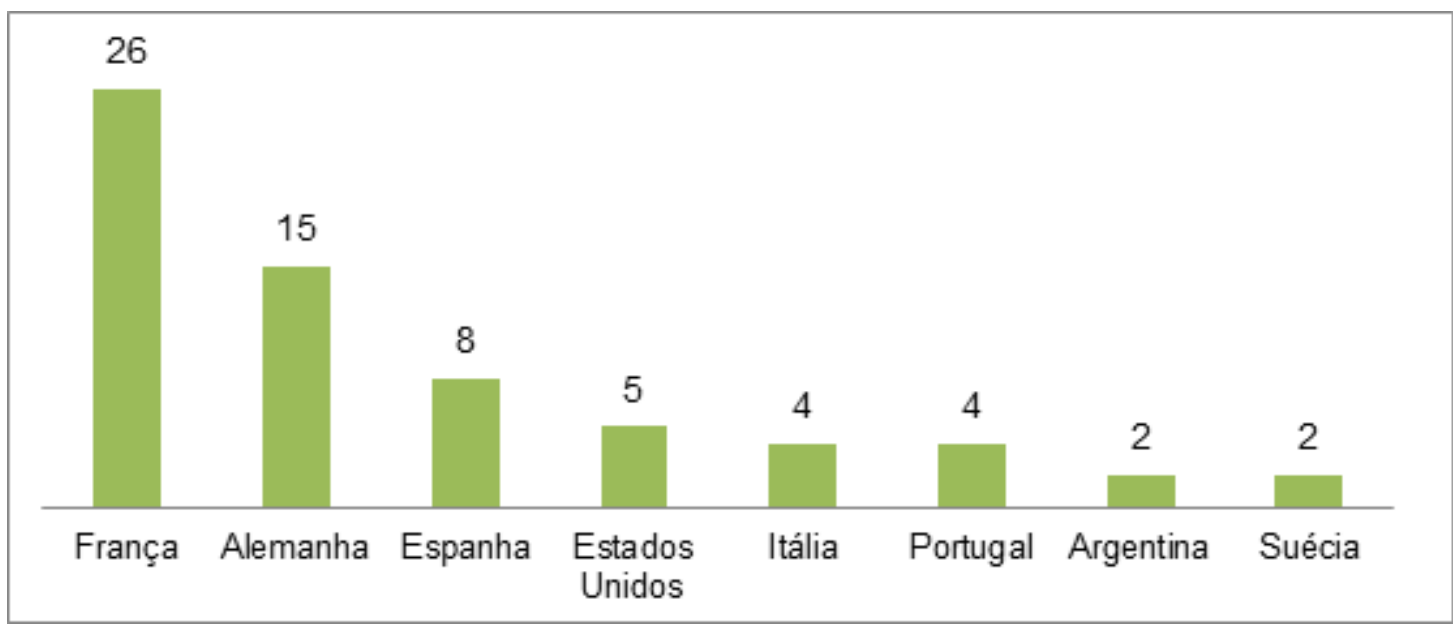

Gráfico 1 País de destino.

Fonte: Elaborado pela autora.

Os estudantes foram questionados em relação a qual era o domínio do idioma falado no país escolhido, tanto antes como depois da viagem. De acordo com as respostas, pode-se concluir que houve um substancial aprimoramento deste, tendo em vista que, antes da viagem, mais da metade dos estudantes possuíam um domínio inexistente ou básico do idioma e apenas $17 \%$ consideravam o seu domínio do idioma como avançado. Após retornarem da viagem, $84 \%$ dos estudantes acreditavam possuir um conhecimento intermediário ou avançado do idioma estrangeiro, sendo que $46 \%$ consideravam possuir um domínio avançado e apenas $2 \%$ voltaram com nenhum conhecimento acerca do idioma.

Em relação ao tempo de estudos no exterior, $81 \%$ dos respondentes ficaram apenas um semestre, o que pode estar relacionado ao fato de que apenas 3 dos 63 respondentes contaram com uma bolsa de estudos durante a mobilidade. No caso dos 60 estudantes que não contaram com nenhum tipo de bolsa, 59 tiveram a ajuda da família para lidar com os gastos relacionados ao intercâmbio e 23 possuíam poupança. 
Em relação à questão de como os estudantes classificariam o suporte oferecido pela universidade receptora durante o programa de mobilidade, apenas 14\% consideraram ruim ou péssimo, enquanto $72 \%$ consideraram o suporte bom ou excelente.

A seguir, são apresentados os objetivos pretendidos pelos respondentes ao realizarem o programa de mobilidade acadêmica. Observa-se a grande importância atribuída aos fatos de conhecer lugares e pessoas novas e de aprender com uma nova cultura. Enquanto isso, o objetivo de se fazer contatos acadêmicos e/ou profissionais foi considerado pela totalidade dos respondentes como pouco ou nada relevante. Os outros objetivos obtiveram classificações bem distribuídas, como pode ser observado no Quadro 2.

\begin{tabular}{|c|l|c|c|c|c|}
\hline Categoria & \multicolumn{1}{|c|}{ Objetivo } & $\begin{array}{c}\text { Nada } \\
\text { relevante }\end{array}$ & $\begin{array}{c}\text { Pouco } \\
\text { relevante }\end{array}$ & Relevante & $\begin{array}{c}\text { Muito } \\
\text { relevante }\end{array}$ \\
\hline \multirow{2}{*}{$\begin{array}{c}\text { Crescimento } \\
\text { pessoal }\end{array}$} & Conhecer lugares e pessoas novas & $0 \%$ & $3 \%$ & $24 \%$ & $73 \%$ \\
\cline { 2 - 6 } & Aprender com uma nova cultura & $2 \%$ & $5 \%$ & $24 \%$ & $70 \%$ \\
\cline { 2 - 6 } & $\begin{array}{l}\text { "Dar um tempo" da vida que } \\
\text { atualmente levo }\end{array}$ & $22 \%$ & $25 \%$ & $22 \%$ & $30 \%$ \\
\hline \multirow{2}{*}{$\begin{array}{c}\text { Crescimento } \\
\text { profissional }\end{array}$} & $\begin{array}{l}\text { Aprimorar meu conhecimento na } \\
\text { área de estudos }\end{array}$ & $3 \%$ & $27 \%$ & $41 \%$ & $29 \%$ \\
\cline { 2 - 6 } & $\begin{array}{l}\text { Fazer contatos acadêmicos e (ou) } \\
\text { profissionais }\end{array}$ & $5 \%$ & $44 \%$ & $33 \%$ & $17 \%$ \\
\cline { 2 - 6 } & Trabalhar/ganhar dinheiro & $73 \%$ & $27 \%$ & $0 \%$ & $0 \%$ \\
\hline
\end{tabular}

Quadro 2 Objetivos ao realizar o programa de mobilidade acadêmica.

Fonte: Elaborado pela autora.

Conforme descrito na metodologia, para analisarmos os objetivos dos estudantes ao realizarem o programa de mobilidade acadêmica, optou-se por categorizar as respostas dividindo-as em dois grupos: questões acadêmicas e/ou profissionais e questões de crescimento pessoal. Percebe-se que os objetivos da categoria "crescimento pessoal" revelaram-se predominantemente muito relevantes para os respondentes.

Dentre as dificuldades e desafios encontrados pelos estudantes, os problemas relacionados às suas moradias foram considerados por eles como sendo os mais relevantes, principalmente em relação a encontrar um local para morar durante o intercâmbio e, como comentado por um respondente, a se adaptar a uma moradia não muito agradável de viver.

As dificuldades de suporte da UDESC e problemas burocráticos vêm logo a seguir como questões importantes, em ambos os casos sendo consideradas por $16 \%$ dos respondentes como muito relevantes. Neste particular, destacam-se as dificuldades de 
validação das disciplinas na UDESC, considerado por 30\% dos respondentes como relevante ou muito relevante.

As questões relacionadas às diferenças culturais entre o Brasil e os outros países assumem um papel importante, tendo em vista que $40 \%$ dos respondentes consideraram o desafio da adaptação ao ensino no exterior como muito relevante. Um respondente afirmou que precisou dedicar mais horas de estudo para conseguir acompanhar as aulas, considerando que as mesmas eram mais difíceis do que as aulas que ela estava acostumado na UDESC. Em relação à cultura local, outro respondente revelou estranhamentos como lavar roupas fora de casa, diferentes tipos de eletrodomésticos e o fato de os supermercados fecharem às 18 horas e não abrirem aos domingos. Ao contrário do que se poderia imaginar, a adaptação ao clima local e a solidão foram as dificuldades considerados de menor relevância para os respondentes, sendo considerados apenas por 3\% deles como muito relevante, em ambas as situações.

A única questão aberta perguntava como o estudante buscou superar estas dificuldades e desafios. Em geral, os respondentes consideraram essenciais as ajudas de pessoas como seus familiares, amigos, professores, colegas intercambistas e também locais. Mais de uma vez foi citada a ajuda de um buddy estrangeiro, uma "madrinha" ou "padrinho", que é um estudante local que se compromete a ajudar um aluno intercambista com suas dificuldades. Segundo um dos respondentes, sua buddy também o buscou no aeroporto, ajudou-o a comprar um chip de telefone e a instalar a sua internet. Os amigos, tanto brasileiros como intercambistas de outras nacionalidades que já se encontravam instalados, também foram fundamentais a lidar com os problemas do cotidiano.

As universidades também tiveram um papel fundamental na solução dos problemas encontrados, com destaque às universidades receptoras estrangeiras. Não apenas na designação de um buddy para cada intercambista, mas também na resolução de problemas burocráticos. Um dos estudantes também elogiou o apoio da UDESC e de seus professores no momento de escolher quais disciplinas faria no exterior.

Em relação à moradia, o suporte de empresas imobiliárias conveniadas foi uma solução recorrente nas respostas. Ocorreram situações nas quais o estudante não conseguiu definir uma moradia num primeiro instante, muito em função de se tratar de alta temporada. A solução mais recomendada para esta situação é a de hospedar-se em albergues até que se encontre um local definitivo para residir. Para o estudante que não gostou das condições em 
que se encontrava o local onde foi alocado, restou-lhe acostumar-se à situação e adaptar-se com o passar do tempo.

\section{CONSIDERAÇÕES FINAIS}

Investigar o cotidiano de alunos em mobilidade acadêmica no estrangeiro pode sugerir, num primeiro momento, uma análise de dados tão dispersos que talvez não seja possível gerar algum teor científico para os resultados obtidos.

Com efeito, as notórias diferenças culturais entre os países, as questões associadas ao idioma local e o próprio nível de desenvolvimento econômico de cada uma dessas nações estrangeiras podem contribuir diretamente para esta dispersão.

Todavia, os resultados obtidos acabaram por revelar uma importante convergência entre os fatores investigados, considerando que a pesquisa envolveu 63 estudantes distribuídos em 8 diferentes países.

Observou-se que é na categoria de questões de crescimento pessoal em que se encontram os fatores considerados mais importantes durante a experiência de mobilidade, destacando-se os objetivos de conhecer lugares, novas pessoas e aprender com uma cultura diferente. Diante desta perspectiva, pode-se argumentar que a experiência internacional é, predominantemente, vista como uma oportunidade para desenvolver-se como pessoa e, num segundo plano, como um meio de buscar-se conhecimento acadêmico e desenvolvimento profissional.

Dos obstáculos enfrentados pelos estudantes, receberam maior destaque as dificuldades envolvidas nos procedimentos de suporte da UDESC como, por exemplo, identificar a equivalência de disciplinas, validar as disciplinas cursadas no exterior e elencar os documentos estrangeiros necessários ao registro local. Estas questões de procedimento podem estar associadas ao próprio estágio embrionário em que ainda se encontra o processo de internacionalização da UDESC.

Conforme exposto anteriormente, uma boa alternativa para dinamizar este atendimento aos alunos em mobilidade está no oferecimento de um apoio virtual para complementar o tradicional programa de mobilidade acadêmica, tanto antes quanto depois da experiência (BEECK et al., 2007). Utilizando-se do meio eletrônico (home page institucional), a IES pode realizar atividades de orientação e seleção de alunos, organizar cursos preliminares para os estudantes que estão se preparando para a mobilidade, aplicar avaliações ao final do programa 
e oferecer um espaço (blog) para promover a discussão entre alunos que já passaram pela experiência da mobilidade e aqueles que estão demandando algum tipo de informação relacionada.

Uma proposta de pesquisa seria a realização de um estudo de abordagem qualitativa objetivando propor um modelo de gestão de mobilidade acadêmica aplicável à realidade da UDESC, com vistas a dar suporte a este fenômeno.

Finalmente, cabe destacar que o processo de internacionalização da UDESC constituirá uma pauta recorrente para as próximas gestões. Neste particular, a gestão da mobilidade acadêmica assume um papel fundamental, não só pelo número crescente dos seus participantes, mas também pelos prováveis resultados para as atividades de ensino e de pesquisa.

\section{REFERÊNCIAS}

BEECK, Ilse Op de; et al.. Extending and Supporting Physical Student. Journal Of Business And Society, Bélgica, vol. 20, p. 35-45, 2007.

BETT, Daniela Zanrosso. Jovens Universitários e Intercâmbio Acadêmico. Porto Alegre, 2012. 34f. Monografia (Especialização). Curso de Psicologia, Universidade Federal do Rio Grande do Sul.

ESN - International Exchange Erasmus Student Network. Erasmus programme. Disponível em: <http://www.esn.org/content/erasmus-programme>. Acesso em: 14 ago. 2014.

FOLHA DE SÃO PAULO. Ranking Universitário Folha - RUF. Disponível em: http://ruf.folha.uol.com.br/2014/rankingdeuniversidades/rankingporinternacionalizacao/. Acesso em: 09 Set, 2014.

GRIBBLE, Cate. Policy options for managing international student migration: the sending country's perspective. Journal of Higher Education Policy and Management, Melbourne, v. 30 , n. 1, p. 25-39, feb. 2008.

HAIR Jr., Joseph F.;BABIN, Barry; MONEY, Arthur H.; SAMOUEL, Phillip. Fundamentos de Métodos de Pesquisa em Administração. Porto Alegre: Bookman, 2005.

INSTITUTE OF INTERNATIONAL EDUCATION. International Students in the United States and Study Abroad by American Students are at All-Time High. Disponível em: $<$ http://www.iie.org/en/Who-We-Are/News-and-Events/Press-Center/PressReleases/2013/2013-11-11-Open-Doors-Data>. Acesso em: 15 ago. 2014.

KILEY, Margaret; AUSTIN, Andy. Australian postgraduate research students still prefer to 'stay at home': reasons and implications. Journal Of Higher Education Policy And Management. Austrália, p. 351-362. nov. 2008. 
KNIGHT, Jane. Internationalization Remodelled: Definitions, Rationales and Approaches. Journal of Studies in International Education, Vol. 8, n. 1, 2004.

LAUS, Sônia Pereira. A internacionalização da educação superior: Um estudo de caso da Universidade Federal de Santa Catarina. Salvador, 2012. 332f. Tese (Doutorado) - Curso de Administração, Universidade Federal da Bahia.

LEE, Thomas. Internationalization of the Undergraduate Business Program: Integrating. Business Education Innovation Journal. Boston, p. 74-82. jun. 2013.

LLEWELLYN-SMITH, Catherine; MCCABE, Vivienne S. What Is the Attraction for Exchange Students: the Host Destination or Host University? Empirical Evidence from a Study of an Australian University. International Journal of Tourism Research. Adelaide, Austrália, v. 10, p. 593-607, out. 2008.

MADLENA, Nen; DAN, Popescu; IULIA, Chivu. Student Mobility in european programmes. Compliance with the criteria from the european quality charter for mobility 2000-2006.

Economic Science Series, Budapest, vol. 17, p. 453-458. dec. 2008.

MINISTÉRIO DO TURISMO. Turismo de estudos e intercâmbio: orientações básicas. 2a Edição. Acesso em 13 de Agosto, 2014, de http://www.turismo.gov.br.

MCCARTHY, Erin E; SEN, Arup K.; GARRITY, Bonnie Fox. Factors that influence canadian students' choice of higher education institutions in the United States. Business Education \& Accreditation, Nova Iorque, v. 4, n. 2, p. 85-95, 2012.

SALLES, Nelci Maria. Programas de intercâmbio como agente enriquecedor profissional: análise da contribuição sob a ótica dos alunos do Curso de Graduação em Administração da Universidade Federal de Santa Catarina. Florianópolis, 2008. 109f. Trabalho de Conclusão de Estágio (Graduação em Administração). Curso de Ciências da Administração, Universidade Federal de Santa Catarina.

SEBASTIÁN, J. Cooperación e Internacionalización de las Universidades. Buenos Aires: Biblos, 2004.

UNESCO. Compendio Mundial De La Educación. Comparación de las estadísticas de la educación en el mundo. Québec, 2009.

VAICEKAUSKAS, Tadas; DUOBA, Kestutis; KUMPIKAITE-VALIUNIENE, Vilmante. The role of international mobility in student's core competence development. Kaunas University Of Technology. Lituânia, 2013. p. 847-857. 